\title{
DETERMINATION OF PHYTOCHEMICALS, ANTIOXIDANT ACTIVITY AND BIOCHEMICAL COMPOSITION OF CHINESE MUGWORT (ARTEMISIA ARGYI L.) LEAF EXTRACT FROM NORTHEAST CHINA
}

\author{
AHMED, M. ${ }^{1}-$ Ji, M. ${ }^{1 *}-$ QIN, P. ${ }^{1}-$ GU, Z $.{ }^{1}-$ LIU, Y. $^{1}-$ SiKANDAR, A. ${ }^{1}-$ IQBAL, M. F. ${ }^{2}-$ \\ JAVEED, A. ${ }^{2}-$ SHAFI, J. ${ }^{3}-$ DU, Y. ${ }^{1}$ \\ ${ }^{1}$ College of Plant Protection, Shenyang Agricultural University \\ No. 120 Dongling Road, Shenyang, 110866 Liaoning, China \\ ${ }^{2}$ College of Biosciences and Biotechnology, Shenyang Agricultural University \\ No. 120 Dongling Road, Shenyang, 110866 Liaoning, China \\ ${ }^{3}$ Department of Plant Pathology, University of Agriculture, 38040 Faisalabad, Pakistan \\ *Corresponding author \\ e-mail: jimingshan@163.com; phone: +86-24-8848-7148; fax:+86-24-8834-2315 \\ (Received $8^{\text {th }}$ Jul 2019; accepted $15^{\text {th }}$ Nov 2019)
}

\begin{abstract}
Present study aimed to investigate phytoconstituents, total phenolic and flavonoids content, antioxidant activity and biochemical composition of the leaf extract of Artemisia argyi L. Qualitative analysis was conducted using standard methods however, total phenolic, flavonoids content and antioxidant activity was assessed by Folin-Ciocalteu, aluminium chloride colourimetric method and 1, 1Diphenyl-2-picrylhydrazyl (DPPH) assay, respectively. Compositional analysis was carried out by Gas chromatography-mass spectrometry (GC-MS). The outcome of the qualitative analysis suggested the presence of flavonoids, phenols, terpenoids, steroids, saponins, tannins and flavones except for alkaloids and glycosides. However, total phenols recorded were $16.89,7.45$ and $3.63 \mathrm{mg}$ gallic acid equivalent GAE/g; flavonoids 20.80, 7.13 and $2.42 \mathrm{mg}$ quercetin equivalent QE/g and DPPH inhibition percent was $81.48,65.62$ and $57.78 \%$ from $1^{\text {st }}, 2^{\text {nd }}$ and $3^{\text {rd }}$ extraction, respectively. GC-MS analysis exposed the existence of ten biological compounds corresponding to $99.91 \%$ of the total extract. However, erucylamide (33.42\%), 1-decene, 4-methyl- (12.63\%), myo-Inositol, (10.42\%), $\alpha$-Cadinol (9.13\%) and 2pyrrolidinone $(8.68 \%)$ were the major compounds with five minor compounds. It was concluded that the leaves of A. argyi contain biological constituents responsible for antioxidant properties which can be introduced as a natural antioxidant pharmacologically and as botanical alternative of synthetic chemicals. However further studies are required on identification of specific components responsible for such activities.
\end{abstract}

Keywords: Chemical analysis, Artemisia argyi, total phenols, total flavonoids, DPPH, GC-MS

\section{Introduction}

Free radicals are highly reactive species that can be produced either endogenously in the body or exogenously through ingestion of pollutants or chemicals. These free radicals are beneficial in the process of signaling, regulation of molecules and destruction of bacteria and viruses at physiological levels. However, excessiveness of free radicals in the body causes oxidative stress that negatively amend the cell structures by interacting with DNA, proteins and lipids, may ultimately lead to certain diseases like cancer, atherosclerosis, Parkinson's, stroke, diabetes, rheumatoid arthritis and senile dementia hence, antioxidants perform their function as reducing agents for neutralization of these free radicals (Fang et al., 2002; Lobo et al., 2010; Liu et al., 2011; Wong et al., 2012). Moreover, secondary metabolites, phenolic and flavonoids 
content are beneficial for human health as well as animals and their usefulness is linked to their antioxidant properties (Meot-Duros and Magne, 2009). However, richness of phytoconstituents in plants food which are non-nutritive agents that protect from disease exploitation and interplays with nutrients, dietary material and also contain several properties like antioxidants, anti-microbial and physiological activities (Adesuyi et al., 2012).

Extensive studies have been conducted on antioxidants as preventative or illness curative associated with oxidative stress. They are also used in the food stuff business to protect from food deterioration, and skin aging in the cosmetic industry. Antioxidants also obstruct with the oxidation process because of their activity as scavenging free radicals (Büyükokuroğlu et al., 2001). Although, synthetically prepared antioxidants, such as tert-butyl hydroxytoluene (BHT), tert-butyl hydroxyanisole (BHA) and antibacterial peptides are available for therapeutic and food industry but, they are carcinogenic so, interest in searching for natural antioxidants from natural resources is increasing gradually (Ling et al., 2011). Natural compounds may have great commercial value in the food industry, but their use is limited due to their high cost. Hence, an effective and cost effective preparation of natural antioxidant is the need of time. The selection of an appropriate extraction method for natural antioxidants concerning extraction effectiveness and economic feasibility aspects to non-conventional extraction methods. Solvent extraction is helpful because of ease to conduct, take less time for extraction as well as higher extraction yields to recuperate maximum antioxidant compounds from medicinal plants (Xu et al., 2017).

Artemisia belongs to family Asteraceae is largest and widely found genus throughout the world, is important from medicinal view point and have got increased attention due to phytochemical activities, chemical and biological diversification (Tan et al., 1998). Artemisia species are well known in Chinese traditional herbal medicines and commonly used in the treatments of cancer, inflammation, hepatitis, menstrual disorders, malaria, metabolism disorders, circulatory system and some infectious diseases caused by viruses, bacteria and fungi (Reynold, 1996; Lis-Balchin and Deans, 1997; Adams et al., 2012; Zhang et al., 2014). It comprises of or more than 500 species (Abad et al., 2012) among which, A. argyi is a prevailing species, mostly found in North America, Asia and Europe (Bora and Sharma, 2011). Historically, A. argyi was first recorded in the Liang Dynasty in "'Ming Yi Bie Lu' (Zhou et al., 2000) however, the true region is considered to be Hubei Province in Qizhou County (Li, 2002). Several compounds were reported containing anti-inflammatory properties from $A$. argyi (Choi et al., 2013; Jeong et al., 2014; Zeng et al., 2014; Park et al., 2015). Essential oil extracted from this plant contains antioxidant properties, anti-melanogenic and insecticidal behavior (Lee and Vairappan, 2011; Huang et al., 2012; Zhang et al., 2014). It is also an imperative plant for nutritional concerns contain essential amino acids, vitamin $\mathrm{C}$, polyunsaturated fatty acids, phenolic contents and possess good DPPH scavenging activity (Kim et al., 2015).

Several protocols have been used for the analysis of chemical compounds among which Gas chromatography-mass spectrometry (GC-MS) is a useful methodology to find out different biological compounds. However, biochemical composition of A. argyi oil from flowers and leaves possess major components such as sesquiterpenes, monoterpenes, ketones, alcohols, aromatic components and ethers, etc. (Hu et al., 2013). Moreover, due to its aromatic properties, essential oil of $A$. argyi could play a prominent function in food preservation and safety (Wang et al., 2006). 
Although, some studies have been conducted on $A$. argyi but data on quantitative analysis, antioxidant activity and biologically active compounds of $A$. argyi is not well described. Therefore, the present research work was planned to evaluate phytochemicals, total phenolic contents, flavonoids content, antioxidant potential and investigations on biochemical compounds by GC-MS analysis from crude solvent extract of $A$. argyi for their appliances as a purposeful food and antioxidants source. The study was conducted at the Biopesticides lab at Shenyang Agricultural University Shenyang, Liaoning China during the year 2019.

\section{Materials and methods}

\section{Collection and plant materials preparation}

As aerial parts of the plants tend to have more interesting compounds and most of the photosynthesis/ respiration take place in the aerial parts. Also, most of the secondary metabolites from plants can be produced in leaves. Thus, young leaves of one month old plants were collected from surrounding locations of Shenyang Agricultural University Shenyang, Liaoning China in April 2019 (Fig. la and 1b).

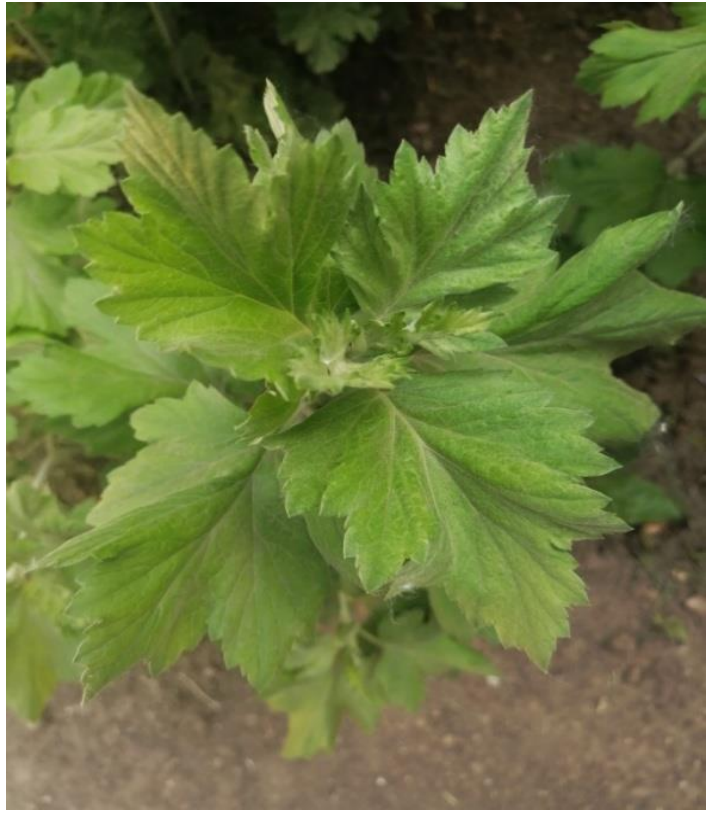

a

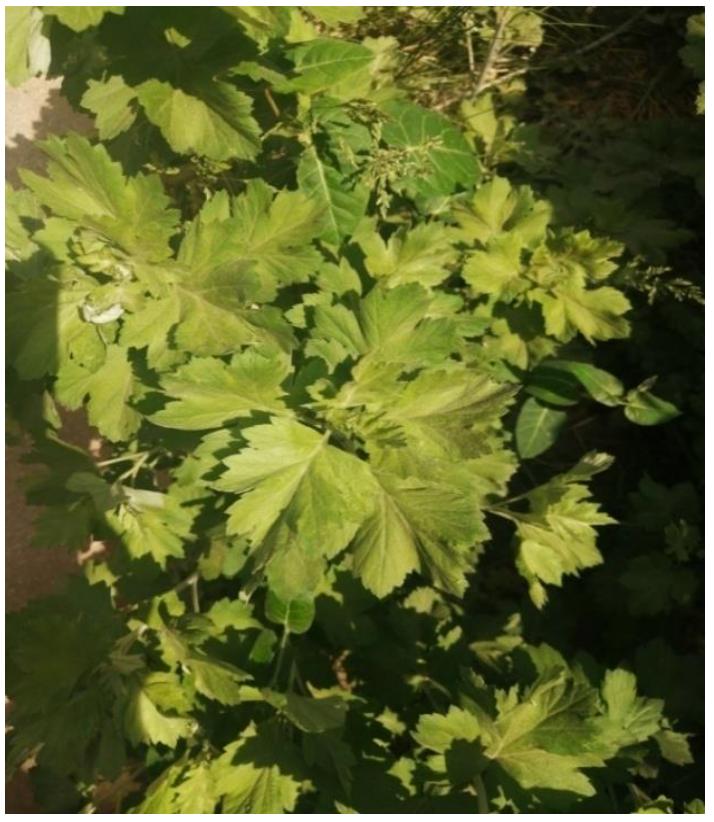

b

Figure 1 a and $\boldsymbol{b}$. Photographic views of A. argyi plant

Ten samples of the same species were collected and mixed together and were washed out beneath tap water to remove impurities and allowed to dry under shade at room temperature. Then, dried leaves were ground to fine powder by electric blender and subjected to successive extraction three times for $72 \mathrm{~h}$ using methanol as solvent (6 $\mathrm{ml} / \mathrm{g}$ ) of plant sample. Contents were filtered and concentrated on rotary evaporator (Buchi Switzerland R-210) to remove solvent from extract. Extract yield was calculated using following Equation 1 and stored at $4{ }^{\circ} \mathrm{C}$ for further use. 


$$
\text { Extract yield }(\%)=\frac{\text { Weight of extract }(\mathrm{g})}{\text { Weight of the sample }} \times 100
$$

\section{Qualitative phytochemical screening}

Methanolic extract of $A$. argyi leaves was subjected to screening tests for the investigation of phytoconstituents using standard methods.

\section{Test for alkaloids}

Half $\mathrm{ml}$ of extract solution was permitted to dry in test tubes and in the consequent reside, $2 \mathrm{ml}$ of $2 \%$ hydrochloric acid $(\mathrm{HCl})$ was added and positioned in water bath at $100^{\circ} \mathrm{C}$ for $15 \mathrm{~min}$. Then, the mixture was filtered on cooling and divided equally into two portions. Addition of few drops of Mayer's reagent into one portion and Dragendoff's to the other portion resulted in turbidity or yellow precipitate confirm alkaloids (Siddiqui and Ali, 1997).

\section{Test for glycosides}

Into $2 \mathrm{ml}$ of extract solution, ferric chloride $\left(\mathrm{FeCl}_{3}\right) 5 \%$ and $2 \mathrm{ml}$ distilled water was added and resultant mixture was placed on water bath for $15 \mathrm{~min}$ and then on cooling 1 $\mathrm{ml}$ of benzene was added, shacked and allowed to settle for $1 \mathrm{~min}$. Next, addition of few drops of concentrated ammonia $\left(\mathrm{NH}_{3}\right)$ resulted in appearance of pink or red color which confirm glycosides (Siddiqui et al., 2009).

\section{Test for terpenoids and steroids}

Briefly, dried extract $0.5 \mathrm{~g}$ was added in to $2 \mathrm{ml}$ of trichloromethane, shacked to dissolve the extract, filtered and placed on ice; following that $2 \mathrm{ml}$ of glacial acetic acid was added. Next, addition of few drops of concentrated sulfuric acid $\left(\mathrm{H}_{2} \mathrm{SO}_{4}\right)$ resulted in emergence of a pink or pinkish brown and, or blue/bluish green color indicate terpenoids and steroids respectively (Siddiqui and Ali, 1997).

\section{Test for flavonoids and flavones}

Into $3 \mathrm{ml}$ extract solution $2 \mathrm{ml}$ of diluted sodium hydroxide $(\mathrm{NaOH})$ was added resulting in yellow colored solution. Solution become colorless on addition of $1 \mathrm{ml}$ of $5 \mathrm{~N}$ hydrochloric acid $(\mathrm{HCl})$ which is the indication of flavonoids however, the appearance of orange color confirms flavones (Sofowora, 1993; Siddiqui et al., 2009).

\section{Test for tannins}

To estimate tannins, $1 \mathrm{ml}$ distilled water and few drops of ferric chloride $\left(\mathrm{FeCl}_{3}\right)$ were added to $0.5 \mathrm{ml}$ extract. From the resulting mixture gallic tannins were confirmed by the appearance of blue color and catecholic tannin by green/black color (Iyengar, 1995).

\section{Test for phenols}

For the detection of phenols, $0.5 \mathrm{~g}$ of extract was added into distilled water and shacked until dissolve and then, $3 \mathrm{ml}$ of $10 \%$ lead acetate $\left(\mathrm{Pb}\left(\mathrm{C}_{2} \mathrm{H}_{3} \mathrm{O}_{2}\right)_{2}\right.$ was added to 
the solution resulted in appearance of white precipitation confirms phenols (Trease et al., 2003).

\section{Test for saponins}

To confirm saponins, addition of $1 \mathrm{~g}$ of extract into $20 \mathrm{ml}$ of distilled water then, shacked strongly resulting in appearance of a foam layer confirms saponins (Siddiqui and Ali, 1997).

\section{Quantitative phytochemical screening}

\section{Total phenolic content (TPC)}

Folin-Ciocalteu reagent assay was employed for assessing the total phenolic stuffing in A. argyi leaves extract. Briefly, mixed $2.5 \mathrm{ml}$ of $10 \%$ Folin-Ciocalteu reagent into 1 $\mathrm{ml}$ plant extract equivalent to $\left(1 \mathrm{mgml}^{-1}\right.$ of methanol) followed by addition of $2 \mathrm{ml}$ of $2 \%$ sodium carbonate $\left(\mathrm{Na}_{2} \mathrm{CO}_{3}\right)$. Then, incubation of substantial mixture was carried out for $15 \mathrm{~min}$ in the absence of light at $28^{\circ} \mathrm{C}$. The mixture's absorbance was determined in ELISA 96-well plate at $765 \mathrm{~nm}$ using an absorbance microplate reader (SpectraMax 190, manufactured in China; designed in USA). Gallic acid $\left(1 \mathrm{mgml}^{-1}\right)$ was used with different concentrations $\left(1,0.50,0.25,0.10,0.05,0.02,0.01\right.$ and $\left.0 \mathrm{mgml}^{-1}\right)$ for standard calibration curve construction and is shown as GAE (gallic acid equivalent) $\mathrm{mgg}^{-1}$ of extract (Aiyegoro and Okoh, 2010). Experiment was replicated three times.

\section{Total flavonoid contents (TFC)}

Total flavonoids contents in the A. argyi leaves extract were determined through aluminium chloride colourimetric method. Briefly, $1 \mathrm{ml}$ of extract equivalent to $\left(1 \mathrm{mgml}^{-1}\right.$ of methanol) was added in to $3 \mathrm{ml}$ methanol, $0.2 \mathrm{ml} 1 \mathrm{M}$ potassium acetate $\left(\mathrm{CH}_{3} \mathrm{COOK}\right), 0.2 \mathrm{ml} 10 \%$ aluminium chloride $\left(\mathrm{AlCl}_{3}\right)$ and distilled water $5.6 \mathrm{ml}$. Then, incubated the resulting mixture for half an hour at $28^{\circ} \mathrm{C}$ in the dark. After that, absorbance was calculated in ELISA 96-well plates at $420 \mathrm{~nm}$ on absorbance microplate reader (SpectraMax 190, manufactured in China; designed in USA). Quercetin was used as the standard $\left(1 \mathrm{mgml}^{-1}\right)$ to obtain standard curve at different concentrations $(1,0.50$, $0.25,0.10,0.05,0.02,0.01$ and $\left.0 \mathrm{mgml}^{-1}\right)$. Results were expressed as quercetin equivalent (QE) $\mathrm{mgg}^{-1}$ of extract (Aiyegoro and Okoh, 2010). Experiment was replicated three times.

\section{DPPH radical scavenging activity}

The antioxidant properties of the extract of $A$. argyi was measured with stable 1,1-diphenyl-2-picrylhydrazyl 'DPPH' (Yu et al., 2003). In brief, extract solution $0.5 \mathrm{ml}$ $\left(1 \mathrm{mgml}^{-1}\right)$ was added to $3.5 \mathrm{ml}$ of freshly made solution of DPPH $\left(0.002 \mathrm{~g}^{2} \mathrm{ml}^{-1}\right.$ methanol) and incubated for half an hour in the dark at room temperature to measure absorbance in ELISA 96-wellplates at $517 \mathrm{~nm}$ on absorbance microplate reader (SpectraMax 190, manufactured in China; designed in USA). The inhibition percent of DPPH was calculated from the decrease of absorbance by using Equation 2. A lower absorbance value represents elevated scavenging activity of free radical. (Zhao et al., 2008).

$$
\operatorname{Inhibition}(\%)=\frac{A_{\text {blank }}-A_{\text {sample }}}{A_{\text {blank }}} \times 100
$$


whereas; $A_{\text {blank }}=($ absorbance of control $) ; A_{\text {sample }}=($ absorbance of samples $)$.

\section{Biochemical analysis by Gas chromatography-mass spectrophotometry (GC-MS)}

Gas chromatography-mass spectrophotometry analysis of crude extract of A. argyi leaves was assessed by using (Agilent 6890-5973N USA), and gas chromatograph (GC) which was equipped with capillary column HP1 model number (TG-5MS) polydimethylsiloxane $(30 \mathrm{~m} \times 250 \mu \mathrm{m} \times 0.25 \mu \mathrm{m})$ interfaced with Hewlett Packard mass selective detector 5973. Gas chromatographic parameters were;

- Temperature fixed for $2 \mathrm{~min}$ at $110^{\circ} \mathrm{C}$ primarily and finally raised to 200 and $280^{\circ} \mathrm{C}$ with increase rate of $10^{\circ} \mathrm{C} / \mathrm{min}$ and $5^{\circ} \mathrm{C} / \mathrm{min}$, respectively.

- Inlet temperature was $250^{\circ} \mathrm{C}$ and $10: 1$ split ratio.

- MS temperature $230^{\circ} \mathrm{C}$.

- MS Quadruple temperature $150^{\circ} \mathrm{C}$.

- Thermal Aux temperature $285^{\circ} \mathrm{C}$.

- Ionization current $60 \mu \mathrm{A}$.

- MS Scan ranges 40-450 units.

- Ionization energy $70 \mathrm{eV}$ and Helium was selected as carrier gas with flow rate: $1.0 \mathrm{ml} / \mathrm{min}$.

Compounds were recognized by elucidation on gas chromatography mass spectrum by literature data or database at Wiley/NIST.98.1 (Joulain and König, 1998; Sparkman, 2005). The comparative yield of each compound was assessed which was based on raw data areas of gas chromatography (GC) with no response factor correction of FID.

\section{Statistical analysis}

Recorded data for total phenols, flavonoids and DPPH inhibition (\%) was analyzed through ANOVA (one-way analysis of variance) and mean values were calculated for significance test by Tukey's HSD at $P=0.05$ level. All statistical processes were administered by different statistical packages with IBM-SPSS statistics 25.0 version.

\section{Results}

\section{Extract yield (\%)}

Extraction from natural plants material is depends upon polarity based solvents and type of the material used. Methanol is a high polarity solvent which is considered as the solvent of choice for higher extract yield, phenolic and flavonoids content. So, for extraction purposes in the current experiment, methanol was selected as solvent. However, according to our findings methanol produced prominent yield in each successive extraction which was $9.91,2.58$ and $1.45 \%$ for $1^{\text {st }}, 2^{\text {nd }}$ and $3^{\text {rd }}$ extraction, respectively (Fig. 2).

\section{Qualitative phytochemical screening}

Preliminary evaluation tests are helpful in bioactive component determination which consequently leads towards discovery and development of drugs and also for agricultural prospects. Tests were conducted for screening of phytochemical like alkaloids, glycosides, terpenoids, flavonoids, flavones, steroids, tannins, phenols and 
saponins from A. argyi leaves. These screening tests led to the identification of bioactive compounds which are important form pharmacological and agricultural point of view. However, the confirmation of a bioactive compound during screening tests was referred as presence (+) and absence (-). Terpenoids were confirmed by pink or pinkish brown color of the solution. Flavonoids and flavones were observed by the conversion of the reaction mixture from yellow to colorless for flavonoids and orange for flavones. Appearance of a blue and green/black color confirms gallic tannin and catecholic tannin respectively. Phenols were confirmed by the appearance of blue or green color in the reaction mixture while, foaming character in extract solution confirms saponins. Phytochemical tests confirmed the existence of tannins, terpenoids, flavonoids, steroids, flavones, phenols and saponins except for alkaloids and glycosides from crude extract of $A$. argyi leaves (Table 1).

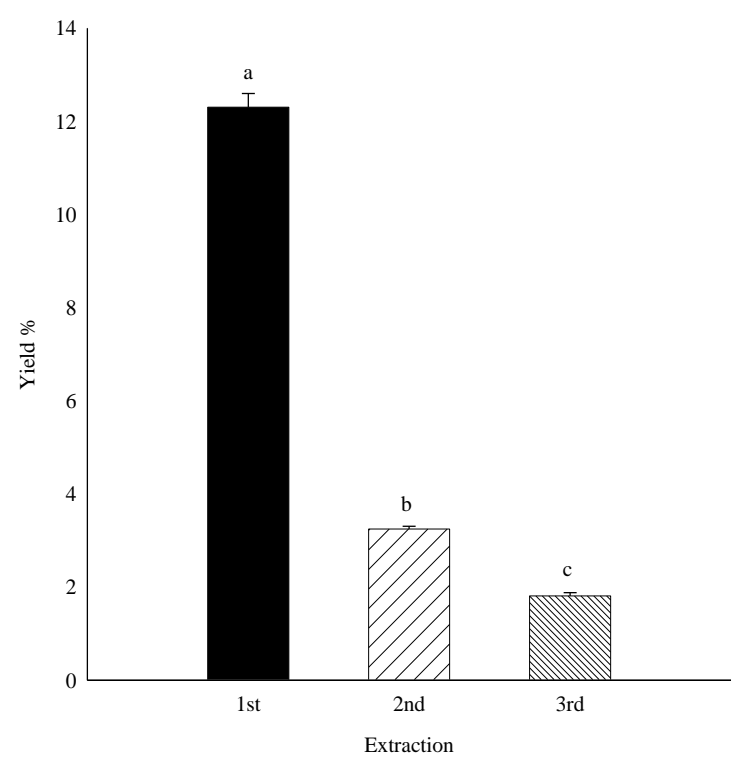

Figure 2. Extract yield produced by methanol by three successive extractions. Values are offered as mean \pm standard error. Same superscripts on the bars designate that values for mean are not significantly different referred to Tukey's HSD test $(P>0.05)$.

Table 1. Qualitative phytochemical screening of A. argyi leaf extract

\begin{tabular}{c|c|c|c}
\hline \multirow{2}{*}{ Phytochemical constituents } & \multicolumn{3}{|c}{ Extraction } \\
\cline { 2 - 4 } & $\mathbf{1}^{\text {st }}$ & $\mathbf{2}^{\text {nd }}$ & - \\
\hline Alkaloids & - & - & + \\
G. Tannins & + & + & + \\
C. tannins & + & + & + \\
Steroids & + & + & - \\
Glycosides & -- & - & + \\
Terpenoids & + & + & + \\
Flavonoids & + & + & + \\
Flavones & + & + & + \\
Phenols & + & + & + \\
Saponins & + & + & \\
\hline
\end{tabular}

Whereas; + presence, -- absence 


\section{Quantitative phytochemical evaluation of total phenolic and flavonoids contents}

The total phenolic content and flavonoid content for three successive extractions are presented in Table 2. Obtained results demonstrated that phenolic content in total were $16.89,7.45$ and $3.63 \mathrm{mg}$ gallic acid equivalent GAE/g for $1^{\text {st }}, 2^{\text {nd }}$ and $3^{\text {rd }}$ extraction respectively while, total flavonoids for $1^{\text {st }}, 2^{\text {nd }}$ and $3^{\text {rd }}$ extraction were $20.80,7.13$ and $2.42 \mathrm{mg}$ quercetin equivalent $\mathrm{QE} / \mathrm{g}$, respectively. Results also revealed that extract afforded phenol and flavonoids in each extraction however, their quantity decreased gradually for each consequential extraction.

\section{DPPH radical scavenging activity}

1,1-Diphenyl-2-picrylhydrazyl (DPPH) is a constant and stable free radical that can easily dissolved in methanol. It showed prominent color absorption on spectrophotometer at $517 \mathrm{~nm}$. The free radical antioxidant molecules were scavenged through contribution of hydrogen molecules and thus the DPPH assay solution's color changed to light yellow resulted in reduction of absorbance. Data obtained by the 1,1-Diphenyl-2-picrylhydrazyl of free radical scavenging commotion is given in Table 2. Results showed that inhibition recorded was $81.48,65.62$ and $57.78 \%$ for $1^{\text {st }}, 2^{\text {nd }}$ and $3^{\text {rd }}$ extraction respectively which clearly demonstrate that inhibition percent did not more influenced by successive extraction from the same sample.

Table 2. Total phenolic content (TPC), Total flavonoids contents (TFC) and DPPH inhibition percent of $A$. argyi leaf extract

\begin{tabular}{|c|c|c|c|c|}
\hline \multicolumn{2}{|c|}{ Solvent extract Extraction } & \begin{tabular}{|c|} 
Total phenolic content mg \\
(GAE/g)
\end{tabular} & \begin{tabular}{|c|}
$\begin{array}{c}\text { Total flavonoid content } \mathrm{mg} \\
(\mathrm{QE} / \mathrm{g})\end{array}$ \\
\end{tabular} & $\begin{array}{c}\text { DPPH Inhibition } \\
(\%)\end{array}$ \\
\hline \multirow{3}{*}{ Methanol } & $1^{\mathrm{st}}$ & $16.89 \pm 0.07^{\mathrm{a}}$ & $20.80 \pm 0.18^{\mathrm{a}}$ & $81.48 \pm 0.41^{\mathrm{a}}$ \\
\hline & $2^{\text {nd }}$ & $7.45 \pm 0.09^{\mathrm{b}}$ & $7.13 \pm 0.08^{\mathrm{b}}$ & $65.62 \pm 0.24^{\mathrm{b}}$ \\
\hline & $3^{\text {rd }}$ & $3.63 \pm 0.11^{\mathrm{c}}$ & $2.42 \pm 0.07^{\mathrm{c}}$ & $57.78 \pm 1.00^{c}$ \\
\hline \multicolumn{2}{|c|}{ Statistics Summary } & $F=5137.75, P=0.000, \mathrm{DF}=2$ & $F=6122.23, P=0.000, \mathrm{DF}=2$ & $F=144.34, P=0.000, \mathrm{DF}=2$ \\
\hline
\end{tabular}

Values are presented as the mean \pm standard error. Same letters within a column specify that mean values are not significantly different according to Tukey's HSD at $(\mathrm{P}>0.05)$

\section{Biochemical analysis}

GC-MS analysis was performed to find out the occurrence of biochemical components in the crude extract of $A$. argyi leaves. Active compounds with their peak area (\%) along with their molecular formula (M.F), molecular weight (M.W) and retention time (R.T) are presented in Table 3.

Table 3. Biochemical composition of A. argyi leaf extract

\begin{tabular}{c|c|c|c|c|c}
\hline Peak \# & R.T & Area\% & Compounds & M.F & $\begin{array}{c}\text { M.W } \\
(\mathbf{g} / \mathbf{M o l})\end{array}$ \\
\hline 1 & 3.485 & 8.68 & 2-Pyrrolidinone & $\mathrm{C}_{4} \mathrm{H}_{7} \mathrm{NO}$ & 85.11 \\
2 & 9.016 & 4.39 & 3-Ethylthiolane & $\mathrm{C}_{6} \mathrm{H}_{12} \mathrm{~S}$ & 116.22 \\
3 & 10.210 & 12.65 & 1-Decene, 4-methyl- & $\mathrm{C}_{11} \mathrm{H}_{22}$ & 154.29 \\
4 & 10.519 & 9.13 & $\alpha-C a d i n o l$ & $\mathrm{C}_{15} \mathrm{H}_{26} \mathrm{O}$ & 222.37 \\
5 & 10.714 & 10.42 & Myo-Inositol, 2-C-methyl- & $\mathrm{C}_{7} \mathrm{H}_{14} \mathrm{O}_{6}$ & 194.18 \\
6 & 16.449 & 5.31 & Phenylephrine & $\mathrm{C}_{9} \mathrm{H}_{13} \mathrm{NO}_{2}$ & 167.21 \\
7 & 16.791 & 6.04 & 3-Chloro-N,N-diethyl-4 nitroanilin & $\mathrm{C}_{10} \mathrm{H}_{13} \mathrm{ClN}_{2} \mathrm{O}_{2}$ & 228.67
\end{tabular}




\begin{tabular}{c|c|c|c|c|c}
8 & 22.902 & 6.60 & Demecolcine & $\mathrm{C}_{21} \mathrm{H}_{25} \mathrm{NO}_{5}$ & 371.43 \\
9 & 23.335 & 3.27 & 2-Ethylacridine & $\mathrm{C}_{15} \mathrm{H}_{13} \mathrm{~N}$ & 207.27 \\
10 & 25.727 & 33.42 & Erucylamide & $\mathrm{C}_{22} \mathrm{H}_{43} \mathrm{NO}$ & 337.58 \\
\hline
\end{tabular}

R.T (retention time); M.F (Molecular formula); M.W (Molecular Weight)

The analysis of compounds from GC-MS, resulted in the detection of several biologically active compounds from methanol extract. Results showed the presence of ten biochemical components corresponding to $99.91 \%$ of total extract. Among the identified compounds erucylamide (33.42\%), 1-decene, 4-methyl- (12.65\%), myoInositol, 2-C-methyl- (10.42\%), $\alpha$-Cadinol (9.13\%) and 2-pyrrolidinone (8.68\%) were the main compounds while, other five compounds were considered as minor compounds because of their low abundance from 3.27-6.60\%. The GC-MS chromatogram showing different peaks of major and minor compounds is presented in Fig. 3.

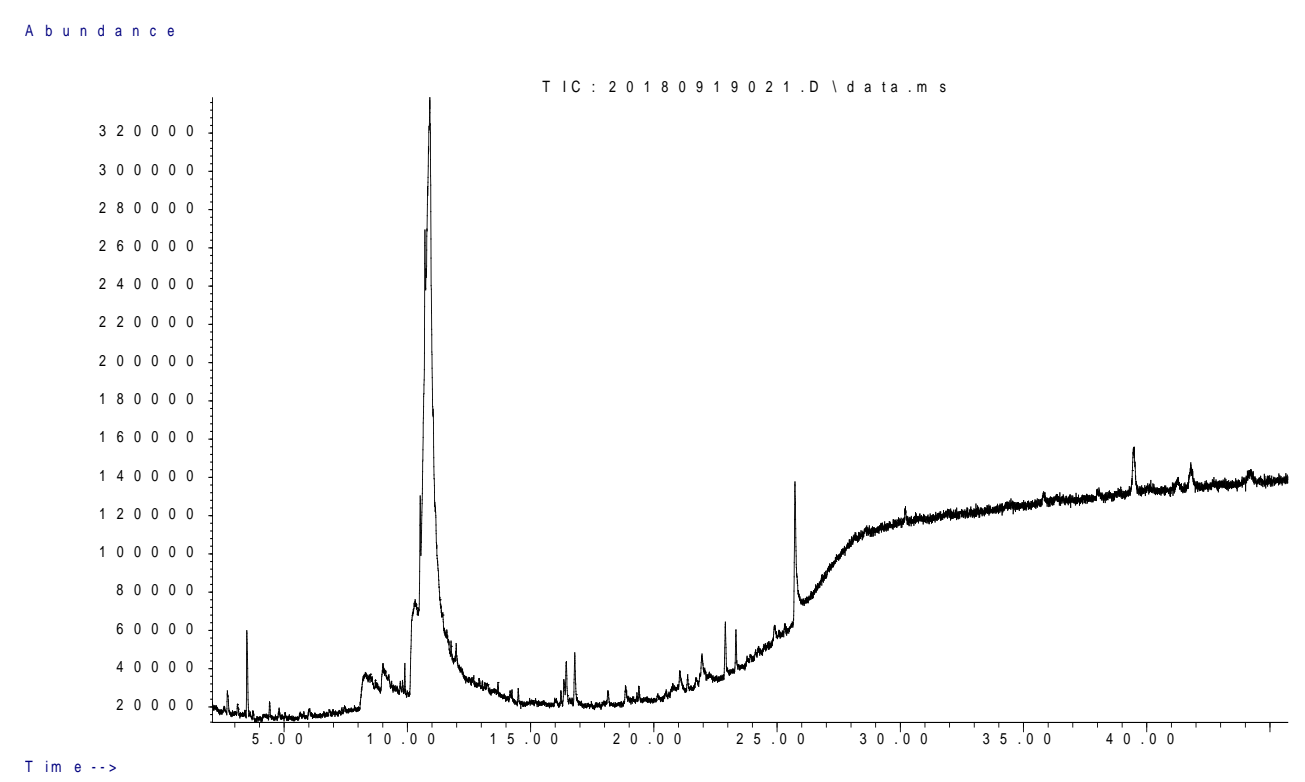

Figure 3. Chromatogram obtained from crude extract of A. argyi leaf

\section{Discussion}

The extraction process of bioactive components is immensely related to the method of extraction, used solvent and the biological and chemical properties of the extracted compounds. According to our findings methanol being a high polarity solvent produced higher extract yield in each successive extraction. However, similar results were documented by Ahmed et al. (2019) that methanol produced elevated extract yield from C. colocynthis and $C$. sativa leaves. Moreover, the result indicated the existence of flavonoids, flavones, saponins, steroid, terpenoids, phenols and tannin with exception of alkaloids and glycosides. The existence of secondary metabolites and a variety of phytoconstituents in natural plant resources could be beneficial for humans in multitude of ways. The phenolic and flavonoids contents exhibited the ability to scavenge free radicals, anti-inflammatory properties, anti-carcinogenic potential, depressurization, immunoregulation, analgesia and anti-lipid peroxidation. However, tannins are well known because of their anti-fungal, anti-tumor, anti-allergic and anti-aging while, 
saponins as well as steroids possess anticancer, anti-inflammatory, antioxidant and have potential for cholesterol reduction and also responsible for insecticidal properties (Prabuseenivasan et al., 2006; Thamaraiselvi and Jayanthi, 2012; Mei et al., 2013; Zhang et al., 2014). Moreover, the existence of phytoconstituents like flavonoid, saponins, tannins, essential oil and steroid of $A$. argyi lead the plant toward increasing potential with nutritional or pharmacological values. However, similar finding were reported by Dhanapal et al. (2016) that dry matter of $A$. argyi contain maximum phenolic and flavonoid contents $234.52 \pm 0.99$ and $737.72 \pm 25.55 \mathrm{mgg}^{-1}$, respectively, Extract also demonstrated $\mathrm{EC}_{50}$ values of DPPH $63.34 \pm 1.10 \mu \mathrm{gmL}^{-1}$.

Mostly flavonoids and phenolic contents were corresponded to antioxidant activities of the extracts. Some studies reported that flavonoids and phenol from plant extracts not only related with antioxidant activities but, some other phytoconstituents such as peptides and polysaccharides may also influenced antioxidant potential of plants (Borkataky et al., 2014). However, our results showed higher phenolic and flavonoids content and high inhibition percent of DPPH radical.

GC-MS analysis of crude extract of $A$. argyi leaves showed the existence of ten chemical compounds responsible for antioxidant activities. Our findings were supported by Chen et al. (2017) who reported 17 chemical compounds by GC-MS analysis including cineole, camphor, borneol and thujone from essential oil of $A$. argyi were found to contain anti-inflammatory activities. Moreover, 33 chemicals constituents were reported from essential oil of $A$. argyi leaves were ether, alcohols, sesquiterpenes, esters, monoterpenes, ketones and aromatic compounds 23.66, 16.72, 15.21, 11.78, $11.63,6.09$ and $5.01 \%$ respectively which account for $90.10 \%$ of its chemical composition and all these compounds contribute to antioxidant activities except for alcohols. Similar findings were documented by Rather et al. (2012) who reported 25 phytoconstituents from Artemisia amygdalina leaf essential oil which was dominated by monoterpenes oxygenated monoterpenes, hydrocarbons and other compounds constituting 43.8, 38.2 and $82.0 \%$ respectively, of whole oil composition. Additionally, essential oil extracted from stem, reported to be contain 32 compounds including monoterpenes, and sesquiterpenes hydrocarbons, oxygenated monoterpenes with ratio 66.1:11.2:12.8\% respectively were responsible for antioxidant profile.

Chemical compounds occupied by $A$. argyi contain curative values against diseases and other humans related issues, such as erucylamide is a monounsaturated fatty acid omega-9 which is necessary for adults with an average of around 500 mgday $^{-1}$ for normal body functioning, accordingly for Food Standards Australia (Zealand, 2003). Demecolcine also called as colcemidis closely related to natural alkaloid known as colchicine is a type of drug which is used in chemotherapy. Phenylephrine is used as a decongestant and available in the market as solid form, an oral medicine and as nasal spray. It can also be used for the prevention of hemorrhoids. Phenylephrine is used as an eye drop to dilate the pupil to facilitate visualization of the retina (Demopulos et al., 2016) and to control blood pressure effects (Shih and Chen, 2004). Another compound Inositol also called as myo-inositol is a carbocyclic sugar which is considered as efficient for the treatment of polycystic ovary syndrome (Monastra et al., 2017), effective in restoration of normal ovary functioning and metabolic stability in patients (Monastra et al., 2017), effectual in restoring FSH/LH ratio and of regularization menstrual cycle (Unfer et al., 2012). $\alpha$-Cadinol is a famous chemical compound contained by $A$. argyi possess anti-fungal properties (Ho et al., 2011) and also used as hepatoprotective (Tung et al., 2011). Various pharmaceutical drugs derived from 2- 
pyrrolidone including Cotinine, Piracetam, Ethosuximide, Doxapram and Povidone are effective medicines while, 2-pyrrolidone also used in ink cartridges (Borase et al., 2014).

However, limited studies have been conducted on quantification of total phenols and flavonoids contents and antioxidant activities from $A$. argyi as pharmacological and alternative of synthetic chemicals and recognition of biologically active components from biomass of crude extract of $A$. argyi. This study fulfills the present research gap and provides comprehensive findings concerning with phytochemicals, phenol and flavonoids contents and antioxidant properties of $A$. argyi leaves.

\section{Conclusion}

Results suggested the presence of important phytoconstituents like flavones, terpenoids, steroids, saponins and tannins, phenols and flavonoids responsible for antioxidant activities which are sources of pharmacological and agricultural applications. Moreover, GC-MS profile presents ten chemical compounds which are linked with antioxidant potential. Therefore, A. argyi might be introduced as an alternative of synthetic antioxidant. However, comprehensive study is required on separation, purification and identification of specific compounds exibit antioxidant activities and their evaluation against insect pest as safer alternative of synthetic chemicals.

Acknowledgment. The financial support provided by National Key Research \& Development Programme of China (2016YFD0200500) is greatly acknowledged.

Conflicts of interests. The authors declare no conflict of interests.

\section{REFERENCES}

[1] Abad, M. J., Bedoya, L. M., Apaza, L., Bermejo, P. (2012): The Artemisia L. genus: a review of bioactive essential oils. - Molecules 17: 2542-2566.

[2] Adams, J. D., Garcia, C., Garg, G. (2012): Mugwort (Artemisia vulgaris, Artemisia douglasiana, Artemisia argyi) in the treatment of menopause, premenstrual syndrome, dysmenorrhea and attention deficit hyperactivity disorder. - Chinese medicine 3: 116.

[3] Adesuyi, A., Elumm, I., Adaramola, F., Nwokocha, A. (2012): Nutritional and phytochemical screening of Garcinia kola. - Advance Journal of Food Science and Technology 4: 9-14.

[4] Ahmed, M., Ji, M., Qin, P., Gu, Z., Liu, Y., Sikandar, A., Iqbal, M. F., Javeed, A. (2019): Phytochemical screening, total phenolic and flavonoids contents and antioxidant activities of Citrullus colocynthis L. and Cannabis sativa L. - Applied Ecology and Environmental Research 17(3): 6961-6979.

[5] Aiyegoro, O. A., Okoh, A. I. (2010): Preliminary phytochemical screening and in vitro antioxidant activities of the aqueous extract of Helichrysum longifolium DC. - BMC complementary and alternative medicine 10: 21 .

[6] Bora, K. S., Sharma, A. (2011): The genus Artemisia: a comprehensive review. Pharmaceutical Biology 49: 101-109.

[7] Borase, H. P., Patil, C. D., Salunkhe, R. B., Suryawanshi, R. K., Salunke, B. K., Patil, S. V. (2014): Transformation of aromatic dyes using green synthesized silver nanoparticles. - Bioprocess and biosystems engineering 37: 1695-1705. 
[8] Borkataky, M., Kakoti, B., Saikia, L. (2014): Influence of total phenolic content and total flavonoid content on the DPPH radical scavenging activity of Costus speciosus (Koen ex. Retz.) Sm. - South Asian Journal of Experimental Biology 4: 261-266.

[9] Büyükokuroğlu, M., Gülçin, I., Oktay, M., Küfrevioğlu, O. (2001): In vitro antioxidant properties of dantrolene sodium. - Pharmacological Research 44: 491-494.

[10] Chen, L.-L., Zhang, H.-J., Chao, J., Liu, J.-F. (2017): Essential oil of Artemisia argyi suppresses inflammatory responses by inhibiting JAK/STATs activation. - Journal of Ethnopharmacology 204: 107-117.

[11] Choi, E., Park, H., Lee, J., Kim, G. (2013): Anticancer, antiobesity, and antiinflammatory activity of Artemisia species in vitro. - Journal of traditional Chinese medicine 33: 92-97.

[12] Demopulos, G. A., Shen, H.-R.,Tedford, C. E. (2016): Stable preservative-free mydriatic and anti-inflammatory solutions for injection. - Google Patents.

[13] Dhanapal, A., Ming, T. W., Aung, H. P., Hao, S. J. (2016): Preliminary screening of Artemisia argyi for antioxidant potentials. - Int. J. Pharmacog. Phytochem. Res 8: 347355.

[14] Dong-Ping, X., Ya, Li., Xiao, M., Tong, Z., Yue, Z., Jie, Z., Jiao-Jiao, Z., Hua-Bin, Li. (2017): Natural Antioxidants in Foods and Medicinal Plants: Extraction, Assessment and Resources. - International Journal of Molecular Sciences 18: 96.

[15] Fang, Y.-Z., Yang, S., Wu, G. (2002): Free radicals, antioxidants, and nutrition. Nutrition 18: 872-879.

[16] Ho, C.-L., Liao, P.-C., Wang, E. I.-C., Su, Y.-C. (2011): Composition and antifungal activities of the leaf essential oil of Neolitsea parvigemma from Taiwan. - Natural product communications 6: 1934578X1100600935.

[17] Hu, Y., Yang, Y., Ning, Y., Wang, C., Tong, Z. (2013): Facile preparation of Artemisia argyi oil-loaded antibacterial microcapsules by hydroxyapatite-stabilized Pickering emulsion templating. - Colloids and Surfaces B: Biointerfaces 112: 96-102.

[18] Huang, H.-C., Wang, H.-F., Yih, K.-H., Chang, L.-Z., Chang, T.-M. (2012): Dual bioactivities of essential oil extracted from the leaves of Artemisia argyi as an antimelanogenic versus antioxidant agent and chemical composition analysis by GC/MS. - International journal of molecular sciences 13: 14679-14697.

[19] Iyengar, M. (1995): Study of Crude Drugs. - 8th. Manipal. India: Power Press.

[20] Jeong, D., Yi, Y.-S., Sung, G.-H., Yang, W. S., Park, J. G., Yoon, K., Yoon, D. H., Song, C., Lee, Y., Rhee, M. H. (2014): Anti-inflammatory activities and mechanisms of Artemisia asiatica ethanol extract. - Journal of Ethnopharmacology 152: 487-496.

[21] Joulain, D., König, W. A. (1998): The atlas of spectral data of sesquiterpene hydrocarbons. - EB-Verlag.

[22] Kim, J. K., Shin, E.-C., Lim, H.-J., Choi, S. J., Kim, C. R., Suh, S. H., Kim, C.-J., Park, G. G., Park, C.-S., Kim, H. K. (2015): Characterization of nutritional composition, antioxidative capacity, and sensory attributes of seomae mugwort, a native Korean variety of Artemisia argyi H. Lev. \& Vaniot. - Journal of analytical methods in chemistry, Volume 2015, Article ID: 916346.

[23] Lee, T. K., Vairappan, C. S. (2011): Antioxidant, antibacterial and cytotoxic activities of essential oils and ethanol extracts of selected South East Asian herbs. - Journal of Medicinal Plants Research 5: 5284-5290.

[24] Li, H. (2002): Research medicinal function of argy wormwood leaf and their development and utilization. - Pri J Chin Materia Med 16: 51-3.

[25] Ling, M., Yili, A., Aisa, H., Bo, Z., Veshkurova, O., Salikhov, S. I. (2011): Isolation of a new peptide from seeds of Apium graveolens indigenous to China. - Chemistry of Natural Compounds 46: 932-934.

[26] Lis-Balchin, M., Deans, S. (1997): Bioactivity of selected plant essential oils against Listeria monocytogenes. - Journal of applied microbiology 82: 759-762. 
[27] Liu, Y.-h., Lv, J.-1., Yuan, K., Yang, P. (2011): Antioxidant Activities of The Extracts of Carya cathayensis Sarg. - Asian Journal of Chemistry 23: 676.

[28] Lobo, V., Patil, A., Phatak, A., Chandra, N. (2010): Free radicals, antioxidants and functional foods: Impact on human health. - Pharmacognosy reviews 4: 118.

[29] Mei, Q., Gao, Y., Tian, S., Dai, W. (2013): The Research and Application of Folium Artemisiae Argyi. - China Press of Traditional Chinese Medicine, Beijing.

[30] Meot-Duros, L., Magne, C. (2009): Antioxidant activity and phenol content of Crithmum maritimum L. leaves. - Plant Physiology and Biochemistry 47: 37-41.

[31] Monastra, G., Unfer, V., Harrath, A. H., Bizzarri, M. (2017): Combining treatment with myo-inositol and D-chiro-inositol (40: 1) is effective in restoring ovary function and metabolic balance in PCOS patients. - Gynecological Endocrinology 33: 1-9.

[32] Park, J.-M., Han, Y.-M., Lee, J.-S., Ko, K. H., Hong, S.-P., Kim, E.-H., Hahm, K.-B. (2015): Nrf2-mediated mucoprotective and anti-inflammatory actions of Artemisia extracts led to attenuate stress related mucosal damages. - Journal of clinical biochemistry and nutrition 56: 132-142.

[33] Prabuseenivasan, S., Jayakumar, M., Ignacimuthu, S. (2006): In vitro antibacterial activity of some plant essential oils. - BMC complementary and alternative medicine 6 : 39.

[34] Rather, M. A., Ganai, B. A., Kamili, A. N., Qayoom, M., Akbar, S., Masood, A., Rasool, R., Wani, S. H., Qurishi, M. A. (2012): Comparative GC-FID and GC-MS analysis of the mono and sesquiterpene secondary metabolites produced by the field grown and micropropagated plants of Artemisia amygdalina Decne. - Acta Physiologiae Plantarum 34: 885-890.

[35] Reynold, J. E. (1996): Martindale-The Extra Pharmacopoeia. - London: The 3.

[36] Shih, J., Chen, K. (2004): Regulation of MAO-A and MAO-B gene expression. - Current medicinal chemistry 11: 1995-2005.

[37] Siddiqui, A. A., Ali, M. (1997): Practical pharmaceutical chemistry. - CBS Publishers \& Distributors.

[38] Siddiqui, S., Verma, A., Rather, A. A., Jabeen, F., Meghvansi, M. K. (2009): Preliminary phytochemicals analysis of some important medicinal and aromatic plants. - Advances in biological research 3: 188-195.

[39] Sofowora, A. (1993): Medicinal plants and traditional medicine in Africa. Ibadan. Nigeria: Spectrum Books Ltd.

[40] Sparkman, O. D. (2005): Identification of essential oil components by gas chromatography/quadrupole mass spectroscopy Robert P. Adams. - Journal of the American Society for Mass Spectrometry 16(11): 1902-1903.

[41] Tan, R. X., Zheng, W., Tang, H. (1998): Biologically active substances from the genus Artemisia. - Planta medica 64: 295-302.

[42] Thamaraiselvi, P., Jayanthi, P. (2012): Preliminary studies on phytochemicals and antimicrobial activity of solvent extracts of Eichhornia crassipes (Mart.) Solms. - Asian Journal of Plant Science and Research 2: 115-122.

[43] Trease, G. E., Evans, W., Pharmacognosy, E. (2003): Baillier Tindall. - ELBS: 479-480.

[44] Tung, Y.-T., Huang, C.-C., Ho, S.-T., Kuo, Y.-H., Lin, C.-C., Lin, C.-T., Wu, J.-H. (2011): Bioactive phytochemicals of leaf essential oils of Cinnamomum osmophloeum prevent lipopolysaccharide/D-galactosamine (LPS/D-GalN)-induced acute hepatitis in mice. - Journal of agricultural and food chemistry 59: 8117-8123.

[45] Unfer, V., Carlomagno, G., Dante, G., Facchinetti, F. (2012): Effects of myo-inositol in women with PCOS: a systematic review of randomized controlled trials. - Gynecological Endocrinology 28: 509-515.

[46] Wang, W., Zhang, X.-k., Wu, N., Fu, Y.-j., Zu, Y.-g. (2006): Antimicrobial activities of essential oil from Artemisiae argyi leaves. - Journal of Forestry Research 17: 332. 
[47] Wong, F.-C., Chai, T.-T., Hoo, Y.-W. (2012): Antioxidation and cytotoxic activities of selected medicinal herbs used in Malaysia. - Journal of Medicinal Plants Research 6: 3169-3175.

[48] Yu, L., Perret, J., Harris, M., Wilson, J., Haley, S. (2003): Antioxidant properties of bran extracts from "Akron" wheat grown at different locations. - Journal of Agricultural and Food Chemistry 51: 1566-1570.

[49] Zealand, F. (2003): Erucic acid in food: a toxicological review and risk assessment. Canberra Food Stand Aust Newzeal: 17-23.

[50] Zeng, K.-W., Wang, S., Dong, X., Jiang, Y., Tu, P.-F. (2014): Sesquiterpene dimer (DSF52) from Artemisia argyi inhibits microglia-mediated neuroinflammation via suppression of NF- $\mathrm{kB}, \mathrm{JNK} / \mathrm{p} 38$ MAPKs and Jak2/Stat3 signaling pathways. - Phytomedicine 21: 298-306.

[51] Zhang, W.-J., You, C.-X., Yang, K., Chen, R., Wang, Y., Wu, Y., Geng, Z.-F., Chen, H.P., Jiang, H.-Y., Su, Y. (2014): Bioactivity of essential oil of Artemisia argyi Lévl. et Van. and its main compounds against Lasioderma serricorne. - Journal of oleo science 63: 829-837.

[52] Zhao, H., Fan, W., Dong, J., Lu, J., Chen, J., Shan, L., Lin, Y., Kong, W. (2008): Evaluation of antioxidant activities and total phenolic contents of typical malting barley varieties. - Food Chemistry 107: 296-304.

[53] Zhou, F., Qin, L., Lian, J., Zhen, Q. (2000): Chemical constituents, biological activities and plant resources of Folium Artemisia argyi. - J Pharm Pract 2: 96-98. 